\title{
Management of large chronic venous leg ulcers with negative pressure wound therapy
}

\author{
Dominik A. Walczak, Michał Wojtyniak, Rajmund Jaguścik, Joanna Porzeżyńska, Wojciech Fałek , Monika \\ Młynarczyk, Karolina Ptasińska, Leokadia Kozaczek, Bartosz Szymański, Piotr W. Trzeciak
}

\section{CASE REPORT}

\begin{abstract}
Introduction: Venous leg ulcers (VLU) occur in $1 \%$ of the adult population and are associated with chronic disability, diminished quality of life and high health-care costs. Treatment is often slow, difficult and recurrence is high because of inappropriate conditions of the wound bed.

Patients and Methods: This study involves 14 patients with chronic venous ulcers larger than $100 \mathrm{~cm}^{2}$ treated with negative pressure wound therapy (NPWT). Patients underwent a radical debridement of all devitalized tissues and partial stripping of an insufficient great saphenous vein in the first operation. After adequate haemostasis, NPWT kit was applied. Once the wounds were determined to be clean and adequate granulation tissue formation was achieved, split-thickness skin grafts were applied. Dressing impregnated with neutral triglycerides and silver ions was used as a first layer and the black polyurethane NPWT foam was applied over it. The pain assessment was performed for 7 patients using $10 \mathrm{~cm}$ visual analog scale (VAS).

Results: The mean number of NPWT dressing changes prior to grafting was 5.8. The mean number of NPWT foam changes was 2.8 after skin grafting. We accomplished complete healing of $\mathbf{9 2 \%}$ of applied skin grafts surface. One patient had recurrence of venous ulcers in the follow-up period. Moreover, one patient required regrafting.

Conclusions: The application of NPWT provides quick wound-bed preparation and high graft take in venous ulcer treatment.
\end{abstract}

Keywords-venous ulcers, negative pressure wound therapy, chronic wound, chronic venous insufficiency, skin graft, silver, pain

\section{INTRODUCTION}

T HE venous leg ulcers (VLU) occur in $1 \%$ of adult population and are associated with chronic disability, diminished quality of life and high health-care costs. Chronic venous insufficiency is the main cause of venous ulcers development.$^{1}$ Increased pressure in the venous system lead to elevated pressure in the capillaries. That allows large molecules and cells to escape into the interstitial fluid. Accumulation of blood cells and fibrinogen deposits inhibits collagen production and plugging the capillaries which lead to tissue ischaemia. Secretion of growth factors, cytokines

Manuscript received 26.07.2016; revised 10.11.2017. This work did not receive any financial support. Authors declare no conflict of interest.

Author affiliations: Oddział Chirurgiczny Ogólny Szpital Wojewódzki im. Jana Pawła II w Bełchatowie, (DAW, MW, RJ, JP, WF, MM, KP, LK, BS, PWT)

*Correspondence to: Dominik A.Walczak: drdominikwalczak@gmail.com and matrix metalloproteinases is deregulated. All these unfavourable factors disrupts the skin's microcirculation, stimulate inflammation and create a non-healing environment. ${ }^{2]}$ Treatment is often slow, difficult and challenging. Poor prognostic factors include large size of the ulcer and prolonged duration. Moreover, the recurrence rates may be as high as $70 \%$.

The best clinical outcomes are achieved through a multimodal care pathway, which includes nutrition, debridement, vascular surgical intervention and compression therapy along with advanced wound management. $]^{3 / 4}$

The negative pressure wound therapy (NPWT) also known as the vacuum-assisted closure (VAC) is very fast developing method of the wounds treatment. It perfectly executes TIME rule (T- tissue debridement, I- infection and inflammation control, $\mathrm{M}$ - moisture balance and $\mathrm{E}$-epidermalization stimulation). The beneficial effects of NPWT on the wound healing include: mechanical drainage, moist environment, reduction of swelling, stimulation of granulation tissue formation, increase in local blood, neoangiogenesis, reduction of bacterial colonization!

\section{PAtients And Methods}

From March 2012 to December 2015, 31 patients with chronic venous ulcers were treated with NPWT at the Department of General Surgery, John Paul II Memorial Hospital in Bełchatów. The venous origin of the ulcer was confirmed by the venous Doppler sonography and ABI measurement. Patients with diabetic or ischaemic ulcers and patients with arterial insufficiency of the lower extremity $(\mathrm{ABI}<0,9)$ were not included in the study. Finally, 14 patients with venous ulcers larger than $100 \mathrm{~cm}^{2}$ were qualified to the retrospective analysis. The cultural swab was taken from ulcers on the admission day. The antibiotics were administered according to culture and susceptibility test results. The surface of wound was measured by projection of the ulcers onto transparent foil with preprinted $1 \mathrm{~cm}^{2}$ measures. Half/squares were rounded up to $1 \mathrm{~cm}^{2}$.

At the beginning of hospital stay, crossectomy and partial stripping of insufficient great saphenous vein (up to ulcer level) were performed in all patients. The insufficient perforator veins were also ligated if detected. Moreover all patients underwent a radical debridement of all necrotic tissues, fibrin 
Table I

CHARACTERISTICS OF THE PATIENTS

\begin{tabular}{|c|c|c|c|c|c|c|c|}
\hline & $\begin{array}{l}\text { Patient } \\
\text { Age }\end{array}$ & Sex & $\begin{array}{l}\text { Duration of the } \\
\text { ulcer (years) }\end{array}$ & $\begin{array}{l}\text { Surface of the ul- } \\
\text { cer }\left[\mathrm{cm}^{2}\right]\end{array}$ & 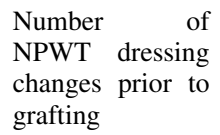 & $\begin{array}{lr}\text { Number } & \text { of } \\
\text { NPWT } & \text { dressing } \\
\text { changes } & \text { after } \\
\text { grafting } & \end{array}$ & $\begin{array}{l}\text { Percentage of vital surface } \\
\text { of mesh grafts }\end{array}$ \\
\hline 1 & 58 & $\mathrm{~F}$ & 3 & 220 & 6 & 2 & 99 \\
\hline 2 & 60 & $\mathrm{~F}$ & 4 & 345 & 5 & 2 & 95 \\
\hline 3 & 75 & $\mathrm{~F}$ & 20 & 180 & 3 & 4 & 98 \\
\hline 4 & 50 & $\mathrm{~F}$ & 10 & 270 & 10 & 3 & 90 \\
\hline 5 & 69 & M & 7 & 320 & 8 & 3 & 90 \\
\hline 6 & 70 & M & 5 & 110 & 6 & 2 & 93 \\
\hline 7 & 58 & M & 6 & 105 & 4 & 2 & 99 \\
\hline 8 & 62 & M & 3 & 150 & 8 & 4 & 88 \\
\hline 9 & 73 & $\mathrm{~F}$ & 1 & 110 & 3 & 3 & 9 \\
\hline 10 & 56 & $\mathrm{~F}$ & 2 & 135 & 3 & 3 & 95 \\
\hline 11 & 67 & M & 3 & 120 & 5 & 2 & 90 \\
\hline 12 & 59 & $\mathrm{~F}$ & 4 & $720 *$ & 9 & 3 & 96 \\
\hline 13 & 80 & $\mathrm{~F}$ & 1 & 280 & 5 & 3 & 95 \\
\hline 14 & 60 & $\mathrm{~F}$ & 1 & 190 & 6 & 3 & 70 \\
\hline
\end{tabular}

* venous ulcers of both legs

deposits and ointment remained during the first operation (Fig. 1)A,B (Fig. 2)A (Fig. 4)A,B. The polyurethane foam (VivanoMed Foam, PAUL HARTMANN AG, Germany) was applied to the ulcer and the pump was set to a continuous negative pressure of $-120 \mathrm{~mm} \mathrm{Hg}$. Dressings were changed every second day. To improve patient comfort during the dressing change - $1 \%$ lidocaine was administered into the foam 30 minutes earlier. After 48 hours, the pressure mode was switched to intermittent negative pressure at $120 \mathrm{mmHg} /-20 \mathrm{mmHg}$. Once the wounds were determined to be clean by clinical assessment and adequate granulation tissue formation was achieved - the meshed split-thickness skin grafts (SGTS) were applied (Fig. 1) C,D (Fig. 2)B (Fig. 3)B (Fig. 4)C. The Atrauman AG (non-adherent, polyester tulle, impregnated with neutral triglycerides and silver ions, PAUL HARTMANN AG, Germany) was used as a primary dressing for skin grafts and covered with NPWT dressing kit with continuous negative pressure of $75-100 \mathrm{~mm} \mathrm{Hg}$ (Fig. 1)E,F. The NPWT dressings were changed on the third day after grafts application. We removed only polyurethane foam, however, the primary dressing (Atrauman AG) remained untouched. The whole dressing (NPWT and polyester tulle with silver ions) was changed on 5th or 6th day after grafts application. Negative pressure wound therapy was continued until it was considered that the grafts uptake was complete (Fig. 1)G (Fig. 2) C (Fig. 3)C (Fig. 4)D.

The pain assessment was performed for 7 patients using $10 \mathrm{~cm}$ visual analog scale (VAS). The third-class medical compression stockings were recommended upon patient's' release from the hospital. The patients were examined on monthly follow-up visits after discharge. (Fig. 1pH (Fig. 2)D(Fig. 3pD.

\section{RESUlTS}

We treated 14 patients ( 9 women and 5 men) with venous ulcers larger than $100 \mathrm{~cm}^{2}$. A mean age of the patients was 64.07 years (range 56-80 years). The ulcer surface area was from $105 \mathrm{~cm}^{2}$ to $720 \mathrm{~cm}^{2}$ (one patient had ulcerations on
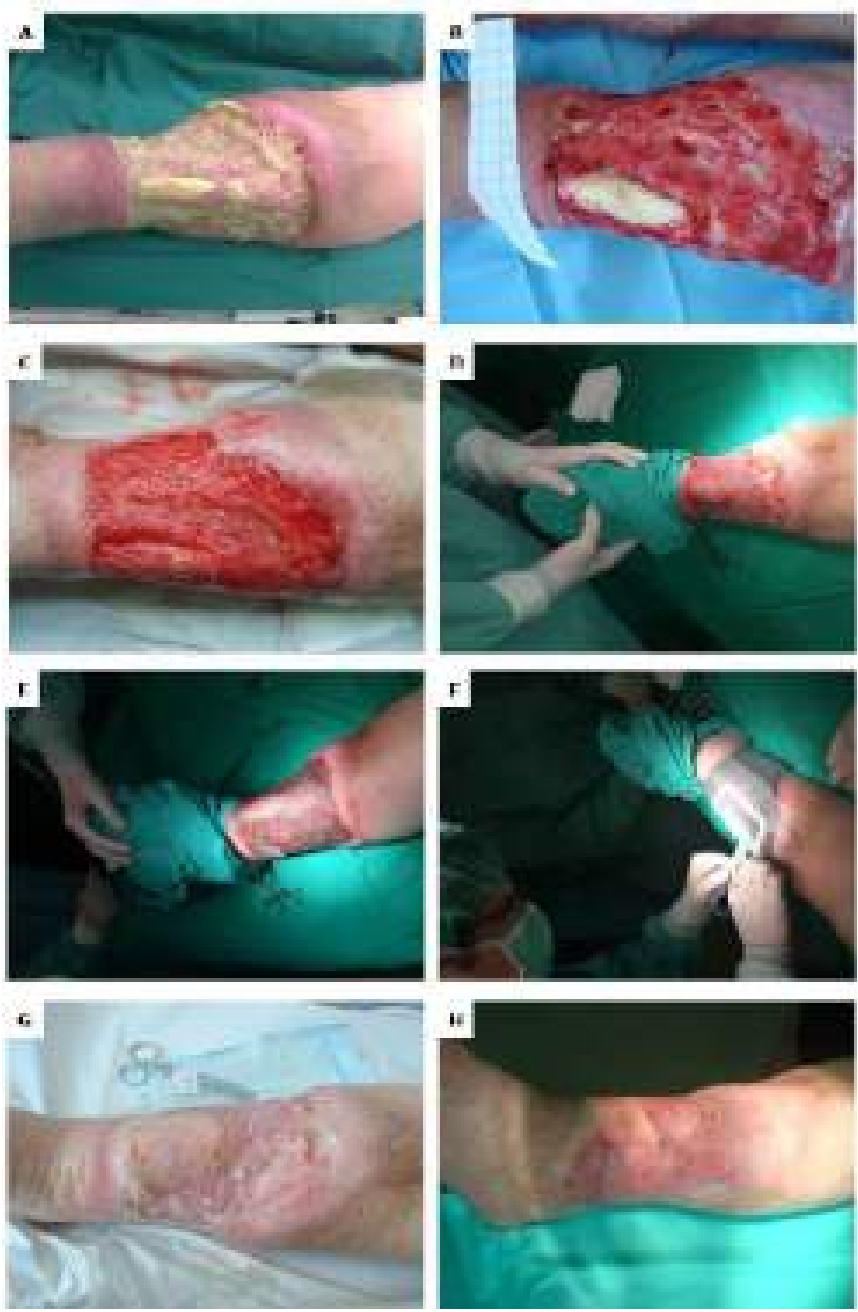

Figure 1. Patient no. 4 in Table 1; a) the wound at the moment of admission; b) the wound after debridement; c) the wound bed filled with granulation tissue after 20 days of NPWT; d,e,f) application of meshed split-thickness skin grafts covered with silver impregnated dressing and NPWT; g) the wound at the moment of discharge from the hospital; h) the wound 3 months after discharge from the hospital; 

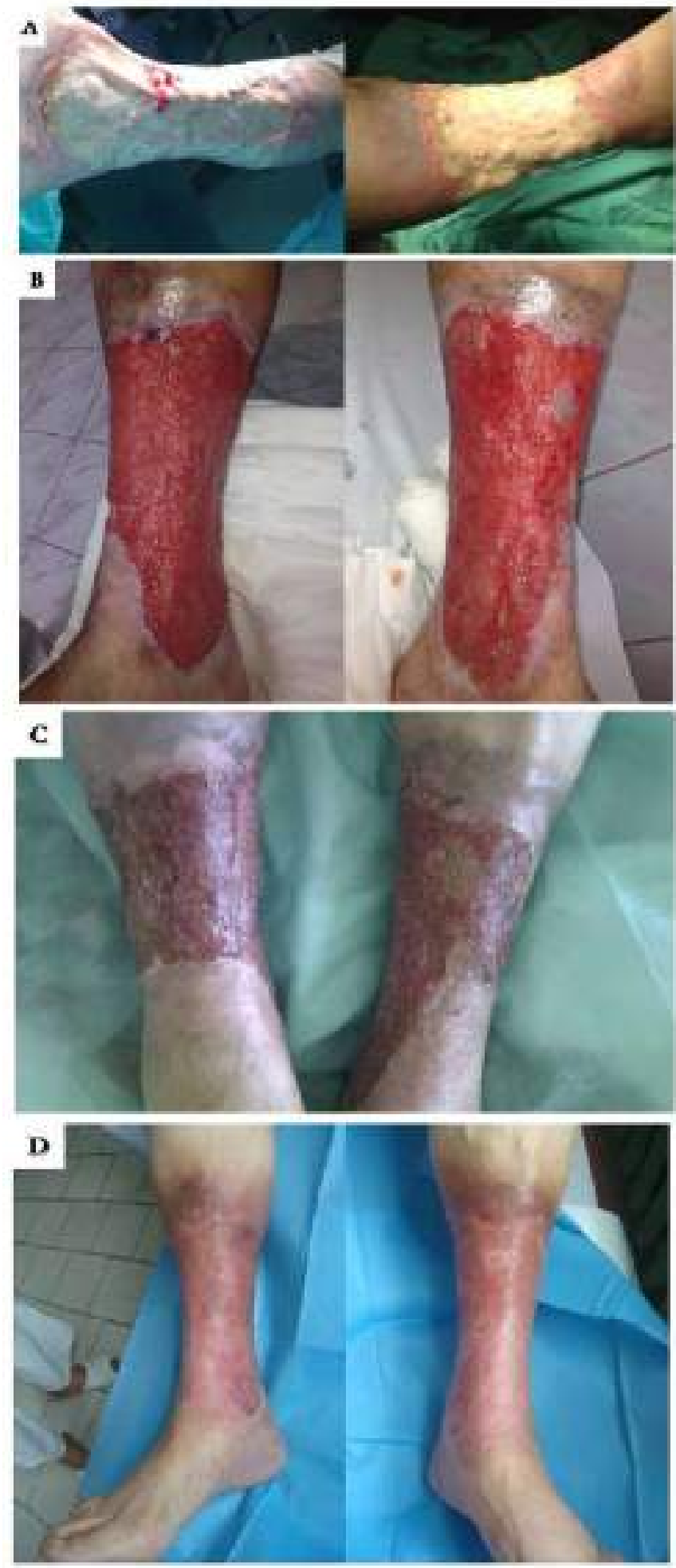

Figure 2. Patient no. 12 in Table 1; a) wounds of both legs at the moment of admission; b) the wounds bed filled with granulation tissue after 20 days of NPWT; c) the wounds at the moment of discharge from the hospital; d) the wound 2 months after discharge from the hospital
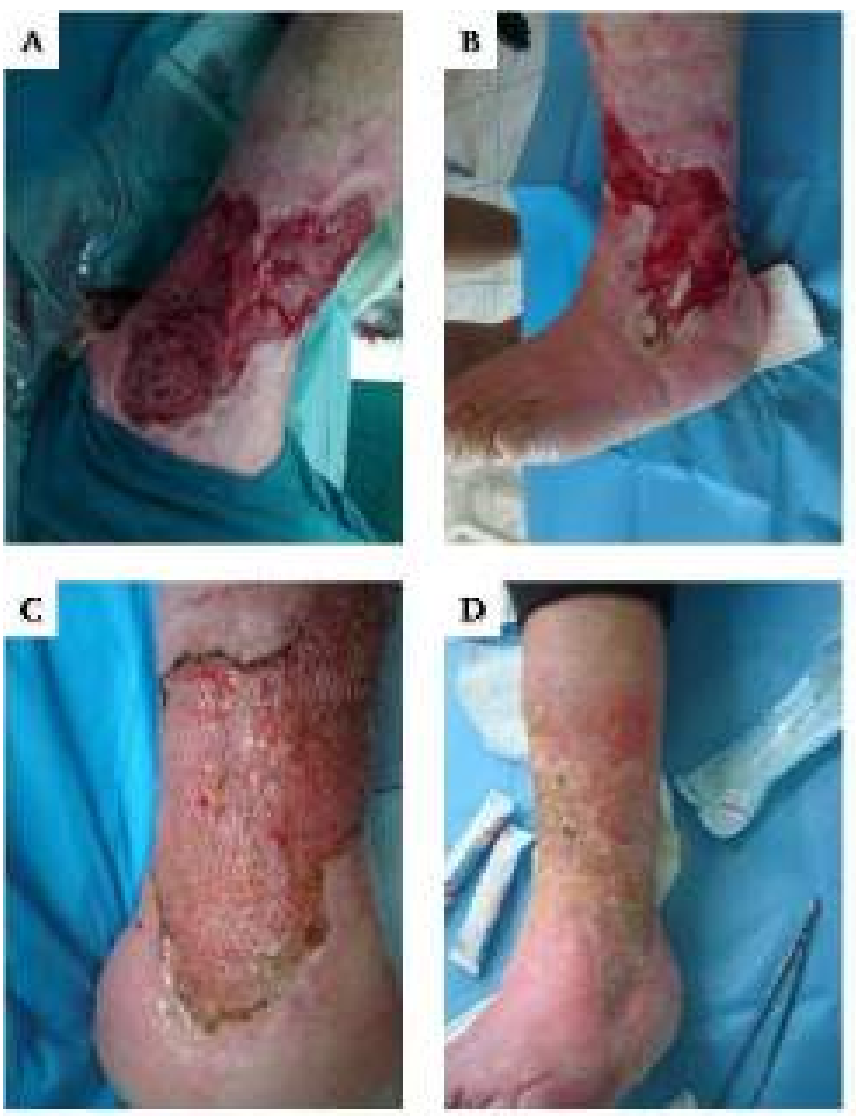

Figure 3. Patient no. 11 in Table 1; a) the wounds at the moment of admission; b) the wound bed filled with granulation tissue after 6 days of NPWT; c) the wounds at the moment of discharge from the hospital; d) the wound 3 months after discharge from the hospital

both legs). The mean ulcer duration prior to admission to our ward was 5 years (range 1-20 years). The mean number NPWT dressing changes prior to skin grafting were 5.8 (3-10 changes) and 2.8 after grafting (2-4 changes). (Tab. I)

All patients reported a little higher pain level during therapy compared with their pain level before treatment and much higher during dressing change so then they required additional painkillers. The pain level decrease during hospitalization even when the foam was changed. (Tab. II)

One patient had recurrence of venous ulcers 2 months after discharge from the hospital. One patient required regrafting due to only $70 \%$ take rate of SGTS (Fig. 4)E.

\section{DISCUSSION}

Experience of vacuum therapy used in medicine has a long history and dates back to the ancient times. However important milestone in vacuum application was introduced by the German surgeon Bier and later by his student Klapp at the beginning of 20th century. Their suction pump was used for removal of the infectious materials in acute inflammatory diseases of the soft tissue and the purulent wounds or diabetic gangrene of feet. The negative pressure therapy for the treatment of wounds was popularized by Argenta and Morykwas in 1997, who described the use of subatmospheric 
pressure through a suction applied to polyurethane foam to improve wound healing. 6

The accurate mechanism of the NPWT action is not clear however it gives the number of beneficial clinical effects. It facilitates wound cleansing, creates a moist environment, establishes the fluid balance by removal of the exudate from the wound, reduces the tissue edema, contracts the wound, mechanically stimulates the wound bed, improves microcirculation, stimulates angiogenesis and the formation of granulation tissue, reduces bacterial load and the risk of infection. $7+11$

The application of the topical negative pressure therapy has been shown to accelerate debridement and promote healing in many different types of wounds. ${ }^{[12}$ Lore' e et al. applied the vacuum-assisted closure to improve the quality of the wound bed in VLU and they noticed that the median percentage reduction in fibrinous tissue was $28 \%$ on day three and $40 \%$ on day six of therapy ${ }^{[13}$ Vuerstaek et al. in a randomized controlled trial showed that the negative pressure was able to prepare wound bed of venous ulcer significantly faster for surgical closure than in the control group. Moreover, costs of conventional wound care were higher than those of NPWT therapy! 14

Table II

PAIN LEVEL DURING NPWT

\begin{tabular}{ll}
\hline $\begin{array}{l}\text { Pain level on } \\
\text { VAS } \\
\text { scale } \\
\text { patients) }\end{array}$ & Time of therapy \\
\hline 3,1 &
\end{tabular}

According to the International Expert Panel on Negative Pressure Wound Therapy (NPWT-EP) recommendations — if compression therapy is not efficacious, the NPWT should be used to prepare the wound for surgical closure or to progress to wound closure by secondary intention. ${ }^{12}$

Following wound bed preparation, closure of venous leg ulcers is commonly carried out by skin grafting. The benefits of NPWT to support skin grafts in different types of wounds were repeatedly reported ${ }^{15}[18$ as well as in venous ulcers! 19 The NPWT demonstrated increase in grafts take rate and improvement in graft quality. Thanks to the negative pressure, the graft adheres to its bed strictly, and interstitial edema resulting from the venous insufficiency is effectively removed. The results of study performed by Korber et al. revealed complete healing in $92.9 \%$ of meshed grafts in which they had applied VAC compared to $67.4 \%$ in the control group without postoperative VAC therapy ${ }^{20}$ Similar improvement was reported by Vuerstaek. 14

In our study, we used polyester tulle, impregnated with neutral triglycerides and silver ions as a primary dressing for skin grafts. The usefulness of silver as an antimicrobial agent has been known since antiquity and is well established ${ }^{21}$ The antimicrobial effect of silver is mediated by the presence of the highly reactive $\mathrm{Ag}^{+}$cation which is disruptive to many aspects of microorganism metabolism. The mechanism of action includes damage to the bacterial cell wall, blockage of transport and enzyme systems such as the respiratory cytochromes, alteration of proteins and binding of microbial deoxyribonucleic acid and ribonucleic acid to prevent transcription and division. ${ }^{22}$ Silver is regarded as a broadspectrum agent and shows activity against the pathogens such as Stapylocoocus aureus and Pseudomonas spp., which frequently colonizes chronic venous ulcers. ${ }^{23}$

Despite its advantages in treating infected wounds, silver has been demonstrated to be cytotoxic to human keratinocytes and fibroblasts in vitro 2124 However, the clinical correlation to support this finding remains unclear.22] 25 Some authors suggest that the human body has complex homeostatic mechanisms and silver might have different effects in vivo than in vitro 22 However, we believe that antimicrobial characteristics of silver ions preponderate its cytotoxic effect. We tried to combine beneficial effect of $\mathrm{Ag}$ cations with advantages of VAC therapy. This strategy seems to be promising because we accomplished complete healing of $92 \%$ of applied skin grafts surface. Hence, randomized control group studies will be necessary to confirm these hypothesis. Pain is a common side effect of NPWT affecting quality of life and even precluding some patients from continuing with the treatment. Many studies reported significantly higher pain levels during therapy compared with their pain levels before treatment. ${ }^{[27 \mid[29}$ Moreover, high sensation is experienced during dressing change, especially in foam-based NPWT. It may be due to wound bed disruption and mechanical tissue damage when the foam and adhering tissue are torn from the wound bed [30]. One method that has been described to reduce pain is to replace the foam with the gauze. In a randomized study comparing gauzebased and foam-based NPWT, Dorafshar et al. reported that gauze-based NPWT provides a less painful option compared with foam-based NPWT?

This may be due to the lack of tissue ingrowth observed with gauze. Similar observations were made by Fraccalvieri et al ${ }^{31}$ Researchers from Sweden compared the expression of calcitonin gene-related peptide (CGRP) and substance P in the wound bed following NPWT and foam or gauze dressing removal. CGRP and substance $P$ are neuropeptides that cause inflammation and signal pain and are known to be released when tissue trauma occurs. The results of study show that both peptides were more abundant in the wound edge after the removal of foam than the removal of gauze after NPWT?

According to NPWT-EP recommendations, gauze may be chosen in patients more susceptible to pain and may be a means of reducing pain experienced during dressing removal! ${ }^{12}$ Another way to reduce pain reported by the patients during the dressing change is the installation of anesthetic through the suction tubing 30 minutes before. In two double-blind, randomized studies topical lidocaine application was associated with lower score on the $0-10$ visual analog scale for pain during the NPWT sponge removal. 33 34 Some researchers have suggested that NPWT is not more 
painful than conventional dressing. Randomised controlled trial performed by Vuerstaek et al. evaluated outcome in leg ulcer patients receiving NPWT or conventional wound care techniques. The pain levels were found to be similar in both groups during the first 5 weeks of therapy, however, those who received NPWT reported significantly less pain after the fifth week. Authors suggest that although NPWT may be just as painful as other wound treatments, the pain may be less prolonged and only short-term. 14

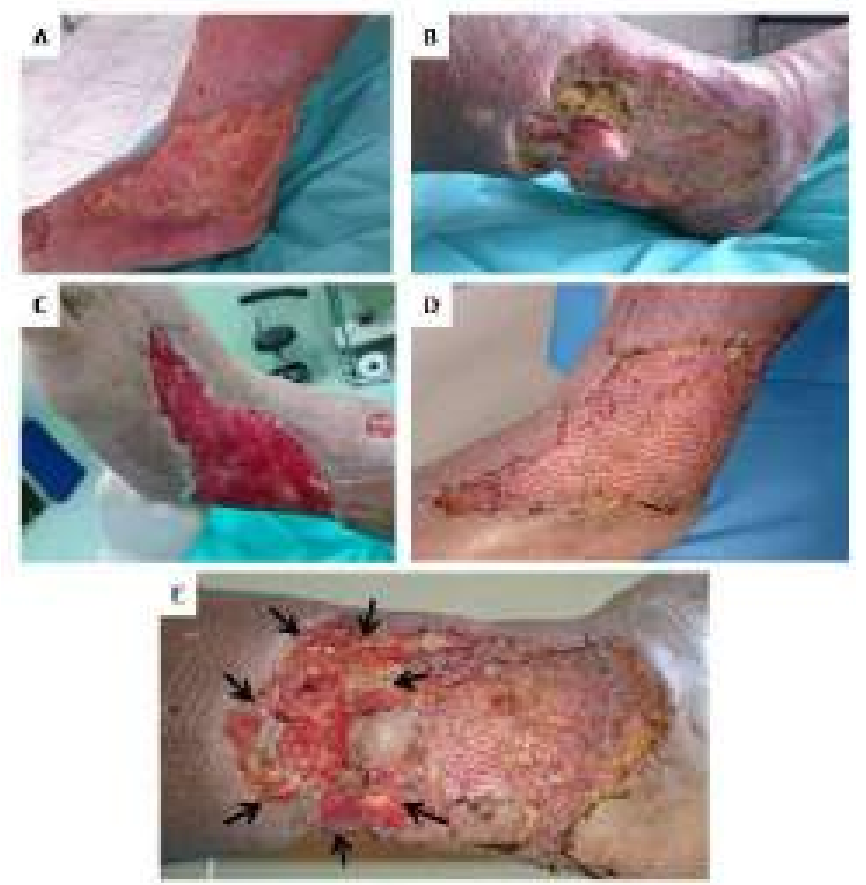

Figure 4. Patient no. 14 in Table 1; a,b) the wounds at the moment of admission; c) the wounds bed filled with granulation tissue after 13 days of NPWT; d, e) healing of only $70 \%$ of applied skin grafts, regrafting was needed on the marked area (black arrows).

\section{CONCLUSIONS}

This study describes effective and efficient use of NPWT in the treatment of huge chronic venous ulcers. The limitation of our study is the lack of control group and the small number of patients. Application of negative pressure wound therapy provided quick wound-bed preparation for surgical closure. Moreover, the NPWT stimulates the process of anastomosis creation between bed and the graft vessels and removes the exudate that may hamper graft's adhering. What are more the bacteria that impair wound healing are eradicated by the antimicrobial properties of silver impregnated dressings? Therefore the NPWT combined with silver dressings demonstrates an increase in graft take rate and improvement in graft quality. Finally, that significantly reduces the time and costs of wound treatment.

\section{REFERENCES}

[1] A. Jawień, M. Szewczyk, A. Kaszuba et al., "Guidelines for the management of chronic venous leg ulceration. recommendations of a multidisciplinary expert group," Leczenie ran, vol. 8, pp. 59-80, 2011.
[2] J. J. Bergan and N. Bunke-Paquette, "The vein book," 2014.

[3] D. D. Wright, "The eschar trial: should it change practice?" Perspectives in vascular surgery and endovascular therapy, vol. 21, no. 2, pp. 69-72, 2009.

[4] O. Egemen, O. Ozkaya, M. B. Ozturk, T. Aksan, Ç. Orman, and M. Akan, "Effective use of negative pressure wound therapy provides quick wound-bed preparation and complete graft take in the management of chronic venous ulcers," International wound journal, vol. 9, no. 2, pp. 199-205, 2012.

[5] Z. Crăiniceanu, S. Olariu, V. Bloancă, I. Farca, F. Bodog, P. Matusz, and T. Bratu, "Continuous negative pressure wound therapy in the treatment of a gigantic trophic leg ulcer," Chirurgia (Bucur), vol. 108, no. 1, pp. 112-5, 2013.

[6] M. Malmsjö and O. Borgquist, "Npwt settings and dressing choices made easy," Wounds International, vol. 1, no. 3, pp. 1-6, 2010.

[7] M. J. Morykwas, L. C. Argenta, E. I. Shelton-Brown, and W. McGuirt, "Vacuum-assisted closure: a new method for wound control and treatment: animal studies and basic foundation." Annals of plastic surgery, vol. 38, no. 6, pp. 553-562, 1997.

[8] M. Malmsjö, R. Ingemansson, R. Martin, and E. Huddleston, "Negative-pressure wound therapy using gauze or open-cell polyurethane foam: similar early effects on pressure transduction and tissue contraction in an experimental porcine wound model," Wound repair and regeneration, vol. 17, no. 2, pp. 200-205, 2009.

[9] N. Kairinos, A. M. Voogd, P. H. Botha, T. Kotze, D. Kahn, D. A. Hudson, and M. Solomons, "Negative-pressure wound therapy ii: negative-pressure wound therapy and increased perfusion. just an illusion?" Plastic and reconstructive surgery, vol. 123, no. 2, pp. 601612, 2009.

[10] A. Wackenfors, J. Sjögren, R. Gustafsson, L. Algotsson, R. Ingemansson, and M. Malmsjö, "Effects of vacuum-assisted closure therapy on inguinal wound edge microvascular blood flow," Wound repair and regeneration, vol. 12, no. 6, pp. 600-606, 2004.

[11] A. K. Greene, M. Puder, R. Roy, D. Arsenault, S. Kwei, M. A. Moses, and D. P. Orgill, "Microdeformational wound therapy: effects on angiogenesis and matrix metalloproteinases in chronic wounds of 3 debilitated patients," Annals of plastic surgery, vol. 56, no. 4, pp. 418-422, 2006.

[12] S. Vig, C. Dowsett, L. Berg, C. Caravaggi, P. Rome, H. BirkeSorensen, A. Bruhin, M. Chariker, M. Depoorter, R. Dunn et al., "Evidence-based recommendations for the use of negative pressure wound therapy in chronic wounds: steps towards an international consensus," Journal of tissue viability, vol. 20, pp. S1-S18, 2011.

[13] S. Loree, A. Dompmartin, K. Penven, D. Harel, and D. Leroy, "Is vacuum assisted closure a valid technique for debriding chronic leg ulcers?" Journal of wound care, vol. 13, no. 6, pp. 249-252, 2004.

[14] J. D. Vuerstaek, T. Vainas, J. Wuite, P. Nelemans, M. H. Neumann, and J. C. Veraart, "State-of-the-art treatment of chronic leg ulcers: a randomized controlled trial comparing vacuum-assisted closure (vac) with modern wound dressings," Journal of vascular surgery, vol. 44, no. 5, pp. 1029-1037, 2006.

[15] S. Llanos, S. Danilla, C. Barraza, E. Armijo, J. L. Pineros, M. Quintas, S. Searle, and W. Calderon, "Effectiveness of negative pressure closure in the integration of split thickness skin grafts: a randomized, doublemasked, controlled trial," Annals of surgery, vol. 244, no. 5, p. 700, 2006.

[16] E. Moisidis, T. Heath, C. Boorer, K. Ho, and A. K. Deva, "A prospective, blinded, randomized, controlled clinical trial of topical negative pressure use in skin grafting," Plastic and reconstructive surgery, vol. 114, no. 4, pp. 917-922, 2004.

[17] L. A. Scherer, S. Shiver, M. Chang, J. W. Meredith, and J. T. Owings, "The vacuum assisted closure device: a method of securing skin grafts and improving graft survival," Archives of Surgery, vol. 137, no. 8, pp. 930-934, 2002

[18] D. M. Vidrine, S. Kaler, and E. L. Rosenthal, "A comparison of negative-pressure dressings versus bolster and splinting of the radial forearm donor site," Otolaryngology-Head and Neck Surgery, vol. 133, no. 3, pp. 403-406, 2005.

[19] C. Stetter, T. Plaza, and P. Von Den Driesch, "Skin grafting of a chronic leg ulcer with combined versajet ${ }^{\mathrm{TM}}$-vac therapy," JDDG: Journal der Deutschen Dermatologischen Gesellschaft, vol. 4, no. 9, pp. 739-742, 2006.

[20] A. Körber, T. Franckson, S. Grabbe, and J. Dissemond, "Vacuum assisted closure device improves the take of mesh grafts in chronic leg ulcer patients," Dermatology, vol. 216, no. 3, pp. 250-256, 2008. 
[21] S.-B. Zou, W.-Y. Yoon, S.-K. Han, S.-H. Jeong, Z.-J. Cui, and W.K. Kim, "Cytotoxicity of silver dressings on diabetic fibroblasts," International wound journal, vol. 10, no. 3, pp. 306-312, 2013.

[22] D. J. Leaper, "Silver dressings: their role in wound management," International wound journal, vol. 3, no. 4, pp. 282-294, 2006.

[23] A. R. Halbert, M. C. Stacey, J. B. Rohr, and A. Jopp-Mckay, "The effect of bacterial colonization on venous ulcer healing," Australasian journal of dermatology, vol. 33, no. 2, pp. 75-80, 1992.

[24] R. Gerry, S. Kwei, L. Bayer, and K. H. Breuing, "Silver-impregnated vacuum-assisted closure in the treatment of recalcitrant venous stasis ulcers," Annals of plastic surgery, vol. 59, no. 1, pp. 58-62, 2007.

[25] D. W. Brett, "A discussion of silver as an antimicrobial agent: alleviating the confusion." Ostomy/wound management, vol. 52, no. 1, pp. 34-41, 2006.

[26] K. Cutting, R. White, and M. Edmonds, "The safety and efficacy of dressings with silver-addressing clinical concerns," International wound journal, vol. 4, no. 2, pp. 177-184, 2007.

[27] A. Apostoli and C. Caula, "Pain and basic functional activites in a group of patients with cutaneous wounds under vac therapy in hospital setting," Professioni infermieristiche, vol. 61, no. 3, pp. 158-164, 2008.

[28] V. L. Schimp, C. Worley, S. Brunello, C. C. Levenback, J. K. Wolf, C. C. Sun, D. C. Bodurka, and P. T. Ramirez, "Vacuum-assisted closure in the treatment of gynecologic oncology wound failures," Gynecologic oncology, vol. 92, no. 2, pp. 586-591, 2004.

[29] K. Waldie, "Pain associated with negative pressure wound therapy."
British Journal of Nursing, 2013.

[30] A. H. Dorafshar, M. Franczyk, R. Lohman, and L. J. Gottlieb, "Prospective randomized study comparing gauze suction negative pressure wound therapy with standard vacuum assisted closure device," pp. 21-25, 2009.

[31] M. Fraccalvieri, E. Ruka, M. A. Bocchiotti, E. Zingarelli, and S. Bruschi, "Patient's pain feedback using negative pressure wound therapy with foam and gauze," International wound journal, vol. 8, no. 5, pp. 492-499, 2011

[32] M. Malmsjö, L. Gustafsson, S. Lindstedt Ingemansson, and R. Ingemansson, "Negative pressure wound therapy-associated tissue trauma and pain: A controlled in vivo study comparing foam and gauze dressing removal by immunohistochemistry for substance $\mathrm{p}$ and calcitonin gene-related peptide in the wound edge." Ostomy-Wound Management, vol. 57 , no. 12 , pp. $30-35,2011$.

[33] T. J. Christensen, T. Thorum, and E. N. Kubiak, "Lidocaine analgesia for removal of wound vacuum-assisted closure dressings: a randomized double-blinded placebo-controlled trial," Journal of orthopaedic trauma, vol. 27, no. 2, pp. 107-112, 2013.

[34] M. Franczyk, R. F. Lohman, J. P. Agarwal, G. Rupani, M. Drum and L. J. Gottlieb, "The impact of topical lidocaine on pain level assessment during and after vacuum-assisted closure dressing changes: a double-blind, prospective, randomized study," Plastic and reconstructive surgery, vol. 124, no. 3, pp. 854-861, 2009. 